\title{
Outcome of delivery in nulliparous teenagers aged less than 17 years: the cameroon university centre hospital experience
} \author{
Anderson Sama Doh ${ }^{3}$, Joseph Nelson Fomulu ${ }^{1}$ \\ ${ }^{1}$ Department of Gynaecology \& Obstetrics, University Hospitals, Yaounde, Cameroon; \\ ${ }^{2}$ Ligue d'Initiative et de Recherche Active pour la Santé et l'Education de la Femme; \\ ${ }^{3}$ Department of Paediatrics, University Hospitals, Yaounde, Cameroon. \\ Email: ${ }^{\text {pmtebeu@yahoo.fr }}$
}

Pierre Marie Tebeu ${ }^{1,2}$, Inoussa Nsangou ${ }^{3}$, Philippe Nana Njotang ${ }^{1}$, Paul Théodore Tjek Biyaga ${ }^{1}$,

Received 21 April 2011; revised 22 May 2011; accepted 29 May 2011.

\section{ABSTRACT}

In a previous study at the Yaoundé-Cameroon University Centre Hospital, we found that delivery at extreme ages of reproductive health was associated with several fetal and maternal risks. We conducted this study aimed at testing the hypothesis that deliveries by teenagers were associated with increased risk. Data collection was retrospective from delivery room registers at between 01/01/1996 and 31/12/2000. Data were collected in singleton pregnancies. The identification of each nulliparous woman aged less than 17 years was followed by that of $\mathbf{4}$ nulliparous women aged 20 - 29 years following her in the order of delivery. Since it was possible to have consecutive nulliparous teenage pregnancies before four deliveries in women in their twenties, we finally compared 65 cases of teenagers delivery with 218 cases of delivery in women aged 20 - 29 years. The difference was considered significant if $p$ value was less than 0.05 . Odd ratio with $95 \%$ confidence interval was used to measure the effect of age on the major outcomes. At univariate analysis, the risk of delivery by caesarean section for teenagers $(\mathbf{2 1 . 5 \% )}$ ) was significantly high compared to women in their twenties $(11.5 \%)$, (OR: 2.1; 95\%CI: 1.0 - 4.1; $p=0.041)$. Similar observation was found for stillbirth delivery with $12.3 \%$ by teenagers compared to $5.0 \%$ by women in their twenties (OR: $2.7 ; 95 \%$ CI: $1.0-7.1 ; p=0.044$ ). The risk of premature delivery by teenagers $(30.8 \%)$ was also significantly increased compared to women in their twenties (12.4\%) (OR: 3.6; 95\%CI: 1.8 - 7.1; $p=$ $0.0002)$. After adjustment for different factors associated with the occurrence of several risks, only pre term delivery remained significantly increased at teenage (OR: 3.7; 95\%CI: $1.8-7.6 ; p=0.003)$. These findings underscore the importance of public health programs in preventing the pregnancy in teenagers, and in developing age-appropriate intervention.

Keywords: Adolescent; Delivery; Risk

\section{INTRODUCTION}

Teenage pregnancy is known to be associated with several risks [1-5]. Nevertheless, teenagers contribute to deliveries all over the world, and according to the literature their proportion varies from $7 \%$ to $25 \%$ of deliveries [6-9]. Many studies have reported more complications of deliveries and poor fetal outcome of pregnancy in adolescents compared to women in their twenties $[7,10]$. Findings from different studies are conflicting. Most of them found an increased risk of delivery by caesarean section, but these findings were not confirmed by other studies $[4,10]$. Conflicting results were also published for the risk of premature delivery, fetal distress, intra uterine fetal death, small for gestational age and post term delivery $[10,11]$. In a previous study at the University Teaching Hospital, Yaoundé-Cameroon, we found that delivery at extreme ages of reproductive health was associated with many fetal and maternal risks [12]. However, we were not able to evaluate the impact of teenage condition on exposure to different risks observed. Thus, it appeared necessary to study the outcome of pregnancy in teenagers in our setting where this topic is little documented.

\section{OBJECTIVE}

The aim of this study was to test the hypothesis that pregnancies in adolescents aged less than 17 years are associated with high risks.

\section{POPULATION AND METHODS}

\subsection{Population}

This was a historical cohort study at the University 
Teaching Hospital Yaoundé-Cameroon. Data collection was retrospective from the delivery room registers between 1/01/1996 and 31/12/2000. Data were collected in singleton pregnancies. The identification of each nulliparous woman aged less than 17 years was followed by that of 4 nulliparous women aged 20 - 29 years following her in the order of delivery. Since it was possible to have consecutive nulliparous teenage pregnancies before four deliveries in women in their twenties, we finally compared 65 cases of teenagers delivery with 218 cases of delivery in women aged 20 - 29 years.

\subsection{Variables}

The maternal risks considered in this study were: delivery by caesarean section and the occurrence of post partum hemorrhage. The fetal outcomes were premature delivery, intra uterine growth retardation, post term delivery, macrosomia, fetal distress and stillbirth. Women were delivered in our hospital regardless of the place of prenatal care.

\subsection{Statistical Analyses}

The software Epi Info 6 was used for analysis. The key question guiding the sample size calculation of this historical cohort study was "what level of exposure to delivery risks the teenagers should be compared to women in their twenties." The sample size calculation was based on the occurrence of a caesarean section incidence of $20 \%$, estimated as quadrupled compared to the low risk parturient. With 1 exposed for 4 unexposed, 325 women were needed to provide $90 \%$ power for a two sided, $5 \%$ test to detect a proportion change that does not exist in both groups. The univariate and multivariate analysis were performed by logistic regression. Odd ratio with $95 \%$ confidence interval was used to measure the effect of age on the major outcomes. The difference was considered significant if the $\mathrm{p}$ value was less than 0.05 .

\section{RESULTS}

Delivery characteristics of women aged less than 17 years $(n=65)$, and those of women in their twenties $(n=$ 218) are described in Table 1. Compared to women in their twenties, teenagers were more likely to deliver prematurely $(30.8 \%$ vs. $12.4 \%)$, to develop post partum hemorrhage ( $7.7 \%$ vs. $2.3 \%$ ), and to be delivered by caesarean section $(21.5 \%$ vs. $11.5 \%)$.

Table 2 presents the result of univariate analysis of delivery risks in teenagers. Delivery by caesarean section for teenagers was significantly increased compared to women in their twenties, (OR: 2.12; 95\% CI: 1.03 $4.4 ; \mathrm{p}=0.041)$. After, adjustment on the pregnancy age and APGAR score, teenage status does not appear as an in- dependent risk factor for caesarean delivery $(P=0.9)$
(Table 3).

The risk of stillbirth delivery by teenagers was significantly increased compared to women in their twenties (OR: 2.7; 95\%CI: 1.03 - 7.14; p = 0.044). After, adjustment on the pregnancy age, teenage status does not appear as an independent risk factor for stillbirth $(\mathrm{P}=0.1)$ (Table 4).

The risk of premature delivery by teenagers was significantly increased compared to women in their twenties (OR: 3.6; 95\%CI: 1.8 - 7.2; p = 0.002). After adjustment for APGAR score, preterm delivery remained significantly increased at teenage (OR: 3.7; 95\%CI: 1.8 7.6; $\mathrm{p}=0.003$ ) (Table 5).

The risk to develop post partum hemorrhage by teenagers was somewhat equal to that of women aged 20 29 years, (OR: 3.5; 95\%CI: $0.9-12.6 ; \mathrm{p}=0.051$ ).

\section{DISCUSSION}

We conducted a historical cohort study. This study showed that when the parturient age is less than 17 years old, the risk of delivery by caesarean section is doubled. Other studies published a higher rate of caesarean section in teenagers compared to the women in their twenties [13-15]. Unfer et al. found a higher incidence of IUGR, acute intrapartum fetal distress and lower birth weight, in the adolescent group [15]. They concluded that the higher number of caesarean sections could be attributed to these fetal conditions as means of preventing fetal death. In the current study, a similar rate of IUGR in both study groups, did not confirm these conditions as cause of caesarean delivery in teenagers. The intrapartum fetal distress as a common indication of caesarean section is subject of controversy because little evidence of improved neonatal or long-term outcome is reported [16]. However, in this study, the severe fetal distress similar in both groups at one minute indicated that there was not more intra partum fetal distress in teenager than in the control group, and the increased risk of caesarean section could not be attributed to the fetal distress. However the high risk of overall stillbirth in teenagers can indicate that some of caesarean section procedure indicated for fetal distress failed in preventing fetal death. Metello et al. found that incidence of Caesarean section was lower in the teenage mothers [17]. They attributed the good results observed to the free and readily available prenatal care and the quality of support from the family or welfare agencies that were involved with the care of teenage mothers. However, this study included all teenagers until 19 years and is therefore a heterogeneous population as shown by several studies [15]. 
Table 1. Maternal, fetal and intrapartum characteristics according to the maternal age.

\begin{tabular}{|c|c|c|c|}
\hline \multirow{4}{*}{ Characteristics } & \multicolumn{3}{|c|}{ Maternal age classes (years) } \\
\hline & $12-16$ & $20-29$ & Total \\
\hline & $\mathrm{N}=65$ & $\mathrm{~N}=\mathbf{2 1 8}$ & $\mathbf{N}=\mathbf{2 8 3}$ \\
\hline & $\mathbf{N}(\%)$ & $\mathbf{N}(\%)$ & $\mathbf{N}(\%)$ \\
\hline Mean age $(S D)$ & $15.51(0.86)$ & $24.08(1.81)$ & - \\
\hline \multicolumn{4}{|l|}{ Gestational age (weeks) } \\
\hline $37-42$ & $35(53.8)$ & $171(78.4)$ & $206(72.8)$ \\
\hline$<37$ & $20(30.8)$ & $27(12.4)$ & $47(16.6)$ \\
\hline$>=42$ & $3(4.6)$ & $8(3.7)$ & $11(3.9)$ \\
\hline Unknown & $7(10.8)$ & $12(5.5)$ & $19(6.7)$ \\
\hline \multicolumn{4}{|l|}{ Oxytocin } \\
\hline Yes & $18(27.7)$ & $64(29.4)$ & $82(29.0)$ \\
\hline No & $47(72.3)$ & $154(70.6)$ & $201(71.0)$ \\
\hline \multicolumn{4}{|l|}{ Misoprostol } \\
\hline Yes & - & $2(0.9)$ & $2(0.7)$ \\
\hline No & $65(100.0)$ & $216(99.1)$ & $281(99.3)$ \\
\hline \multicolumn{4}{|l|}{ Fetal weight } \\
\hline $2500-3999(\mathrm{~g})$ & $45(69.2)$ & $180(82.5)$ & $225(79.5)$ \\
\hline$<2500$ & $14(21.5)$ & $27(12.4)$ & $41(14.5)$ \\
\hline$>4000$ & $2(3.1)$ & $8(3.7)$ & $10(3.5)$ \\
\hline Unknown & $4(6.2)$ & $3(1.4)$ & $7(2.5)$ \\
\hline \multicolumn{4}{|l|}{ IUGR } \\
\hline Yes & $13(20.0)$ & $24(11.0)$ & $37(13.1)$ \\
\hline No & $52(80.0)$ & $194(89.0)$ & $246(86.9)$ \\
\hline \multicolumn{4}{|l|}{ APGAR Score at delivery } \\
\hline $7-10$ & $44(67.7)$ & $164(75.2)$ & $208(73.5)$ \\
\hline $1-6$ & $13(20.0)$ & $37(17.0)$ & $50(17.7)$ \\
\hline 0 & $8(12.3)$ & $11(5.0)$ & $19(6.7)$ \\
\hline Unknown & - & $6(2.8)$ & $6(2.1)$ \\
\hline \multicolumn{4}{|l|}{ PPH } \\
\hline Yes & $5(7.7)$ & $5(2.3)$ & $10(3.5)$ \\
\hline No & $60(92.3)$ & $213(97.7)$ & $273(96.5)$ \\
\hline \multicolumn{4}{|l|}{ Caesarean delivery } \\
\hline Yes & $14(21.5)$ & $25(11.5)$ & $39(13.8)$ \\
\hline No & $51(78.5)$ & $193(88.5)$ & $244(86.2)$ \\
\hline
\end{tabular}


Table 2. Distribution of teenage delivery according the obstetrical characteristics.

\begin{tabular}{|c|c|c|c|c|}
\hline & \multicolumn{2}{|c|}{ Maternal age classes (years) } & \multirow{3}{*}{$\begin{array}{c}\text { Crude Odd } \\
\text { Ratio }^{a}(95 \% \text { CI })\end{array}$} & \multirow{3}{*}{$\mathbf{P}$} \\
\hline & & & & \\
\hline & $N=65$ & $\mathrm{~N}=\mathbf{2 1 8}$ & & \\
\hline \multicolumn{5}{|c|}{ Gestational age (weeks) } \\
\hline $37-42$ & 35 & 171 & $1^{\mathrm{c}}$ & \\
\hline$<37$ & 20 & 27 & $3.6(1.8-7.2)$ & 0.002 \\
\hline$>=42$ & 3 & 8 & $1.8(0.5-7.2)$ & 0.388 \\
\hline Unknown & 7 & 12 & - & \\
\hline \multicolumn{5}{|l|}{ Oxytocin } \\
\hline Yes & 18 & 64 & $1^{\mathrm{c}}$ & \\
\hline No & 47 & 154 & $0.9(0.5-1.7)$ & 0.795 \\
\hline \multicolumn{5}{|l|}{ Misoprostol } \\
\hline Yes & - & 2 & & \\
\hline No & 65 & 216 & - & - \\
\hline \multicolumn{5}{|l|}{ Fetal weight } \\
\hline $2500-3999$ & 45 & 180 & $1^{\mathrm{c}}$ & \\
\hline$<2500$ & 14 & 27 & $2.1(0.9-4.5)$ & 0.071 \\
\hline$>4000$ & 2 & 8 & $1.0(0.1-5.3)$ & 0.629 \\
\hline Unknown & 4 & 3 & - & - \\
\hline \multicolumn{5}{|l|}{ IUGR } \\
\hline Yes & 13 & 24 & $1^{\mathrm{c}}$ & \\
\hline No & 52 & 194 & $2.0(0.9-4.2)$ & 0.060 \\
\hline \multicolumn{5}{|c|}{ APGAR Score at delivery } \\
\hline $7-10$ & 44 & 164 & $1^{\mathrm{c}}$ & \\
\hline $1-6$ & 13 & 37 & $1.3(0.6-2.8)$ & 0.459 \\
\hline 0 & 8 & 11 & $2.7(1.0-7.1)$ & 0.044 \\
\hline Unknown & - & 6 & - & \\
\hline \multicolumn{5}{|l|}{ PPH } \\
\hline Yes & 5 & 5 & $1^{\mathrm{c}}$ & \\
\hline No & 60 & 213 & $3.5(0.9-12.6)$ & 0.091 \\
\hline \multicolumn{5}{|c|}{ Caesarean delivery } \\
\hline Yes & 14 & 25 & $1^{\mathrm{c}}$ & \\
\hline No & 51 & 193 & $2.1(1.0-4.4)$ & 0.041 \\
\hline
\end{tabular}

${ }^{\mathrm{a}}$ Unadjusted; ${ }^{\mathrm{b}}=$ Confidence Interval; ${ }^{\mathrm{c}}$ reference category. IUGR $=$ Intrauterine growth retardation; $\mathrm{PPH}=$ Post partum hemorrhage 
Table 3. Incidence rate of caesarean delivery and Odd ratios according to the maternal age.

\begin{tabular}{cccccc}
\hline $\begin{array}{c}\text { Maternal age } \\
\text { (years) }\end{array}$ & $\begin{array}{c}\text { Total women } \\
(\mathrm{N})\end{array}$ & $\begin{array}{c}\text { N of caesarean } \\
\text { delivery }(\mathrm{N})\end{array}$ & $\begin{array}{c}\text { Incidence rate } \\
(\%)\end{array}$ & $\begin{array}{c}\text { Crude Odd } \\
\text { Ratioa }(95 \% \mathrm{CI})\end{array}$ & $\begin{array}{c}\text { Adjusted Odd Ratiob } \\
(95 \% \mathrm{CI})\end{array}$ \\
\hline $20-29$ & 218 & 25 & 11.5 & $1 \mathrm{c}$ & $1 \mathrm{c}$ \\
$12-16$ & 65 & 14 & 21.5 & $2.12 . *(1.03-4.4)$ & $1.82 * *(0.84-1.49)$ \\
\hline
\end{tabular}

${ }^{\mathrm{a}}$ unadjusted, ${ }^{\mathrm{b}}$ adjusted for pregnancy age and APGAR score, ${ }^{\mathrm{c}}$ reference category. $* \mathrm{P}=0.041 ; * * \mathrm{P}=0.960$

Table 4. Incidence rate of stillbirth and Odd ratios according to the maternal age.

\begin{tabular}{cccccc}
\hline $\begin{array}{c}\text { Maternal age } \\
\text { (years) }\end{array}$ & $\begin{array}{c}\text { Total women } \\
(\mathrm{N})\end{array}$ & $\begin{array}{c}\mathrm{N} \text { of stillbirth } \\
(\mathrm{N})\end{array}$ & $\begin{array}{c}\text { Incidence rate } \\
(\%)\end{array}$ & $\begin{array}{c}\text { Crude Odd } \\
\text { Ratioa }(95 \% \mathrm{CI})\end{array}$ & $\begin{array}{c}\text { Adjusted Odd } \\
\text { Ratiob (95\% CI) }\end{array}$ \\
\hline $20-29$ & 218 & 11 & 5.0 & $1 \mathrm{c}$ & $1 \mathrm{c}$ \\
$12-16$ & 65 & 8 & 12.3 & $2.71 *(1.03-7.14)$ & $2.27 * *(0.84-6.08)$ \\
\hline
\end{tabular}

${ }^{\mathrm{a}}$ unadjusted, ${ }^{\mathrm{b}}$ adjusted for pregnancy age, ${ }^{\mathrm{c}}$ reference category. ${ }^{*} \mathrm{P}=0.044 ;{ }^{* *} \mathrm{P}=0.102$

Table 5. Incidence rate of premature delivery and Odd ratios according to the maternal age.

\begin{tabular}{cccccc}
\hline $\begin{array}{c}\text { Maternal age } \\
(\text { years })\end{array}$ & $\begin{array}{c}\text { Total women } \\
(\mathrm{N})\end{array}$ & $\begin{array}{c}\text { N of premature delivery } \\
(\mathrm{N})\end{array}$ & $\begin{array}{c}\text { Incidence rate } \\
(\%)\end{array}$ & $\begin{array}{c}\text { Crude Odd } \\
\text { Ratioa (95\% CI) }\end{array}$ & $\begin{array}{c}\text { Adjusted Odd } \\
\text { Ratiob (95\% CI) }\end{array}$ \\
\hline $20-29$ & 218 & 27 & 12.4 & $1 \mathrm{c}$ & $1 \mathrm{c}$ \\
$12-16$ & 65 & 20 & 30.8 & $3.61 *(1.82-7.16)$ & $3.70 * *(1.81-7.58)$ \\
\hline
\end{tabular}

${ }^{\mathrm{a}}$ unadjusted, ${ }^{\mathrm{b}}$ adjusted for APGAR score, ${ }^{\mathrm{c}}$ reference category. ${ }^{*} \mathrm{P}=0.002 ; * * \mathrm{P}=0.003$

The behavior of obstetricians with anxiety about the outcome of deliveries in teenagers could have contributed to the indication of operative procedure. This anxiety can influence the premature decision of caesarean delivery intending to reduce the delivery complications. Regardless of the indication, caesarean section remains an important problem in view of the high recurrence rate [18-20].

We found that teenagers have a higher level of preterm delivery compared to women in their twenties. This has been shown by other studies [21,22]. Olausson et al. found that compared to women aged $20-24$ years, mothers who were 17 years or less at first delivery, were at significant increased risk of preterm first delivery, which fortunately shown a larger reduction at next delivery [21]. They concluded that there may be a biological effect of very young maternal age on the risk of pre term birth.

Inadequate antenatal clinic attendance by teenagers, bacterial and parasitic infectious diseases and especially malaria are common in developing countries and are known as risk factors of pre term delivery [23]. The consequence of pre term delivery is critical, as literature report evokes that, according to the degree of pre maturity, $20 \%-30 \%$ of pre term babies died, and 10 to $30 \%$ of those who survive will present neurological complica- tions [24].

The stillbirth rate is also increased in teenagers, and is three times that of the control group. This result is like that of other studies, which found an increased stillbirth rate in teenagers [25]. The poor socio-economic status, the possibility of nutritional anemia, the inadequate prenatal care and emotion are common in developing countries and particularly during adolescence and can be considered as risk factors for stillbirth [26-28]. In the current study, the lost of significance of increasing stillbirth in teenagers after adjustment for pregnancy age class suggests that the high risk of pre term delivery observed in teenagers might contribute considerably in fetal death.

We acknowledge that, some sources of bias are present in this study. Some obstetrical conditions like small pelvis, mal-presentation and premature rupture of membranes which are common in teenagers and can put the parturient as high risk of delivery by caesarean section were not assessed.

\section{CONCLUSIONS}

Teenagers aged 16 or under are at high risk of delivery by caesarean section. Other factors are also significantly increased such as preterm and stillbirth delivery. Studies are needed to determine the specific etiology of any risk 
observed and the possibility of management. These results also underscore the importance of public health programs in preventing pregnancies in teenagers, and in developing age-appropriate interventions.

\section{REFERENCES}

[1] Mahavarkar, S.H., Madhu, C.K. and Mule, V.D. (2008) A comparative study of teenage pregnancy. American Journal of Obstetrics \& Gynecology, 28, 604-607. doi:10.1080/01443610802281831

[2] Maryam, K. and Ali, S. (2008) Pregnancy outcome in teenagers in East Sauterne of Iran. Journal of Pakistan Medical Association, 58, 541-544.

[3] Chang, S.C., O'Brien, K.O., Nathanson, J. and Witter, F.R. (2003) Characteristics and risk factors for adverse birth outcome in pregnant black adolescents. Journal of Pediatrics, 143, 250-257.

doi:10.1067/S0022-3476(03)00363-9

[4] Dos Santos, G.H., Martins, M.G. and Sousa, M.S. (2008) Teenage pregnancy and factors associated with low birth weight. Revista Brasileira de Ginecologia e Obstetrícia, 30, 224-231.

[5] Trivedi, S.S. and Pasrija, S. (2007) Teenage pregnancies and their obstetric outcomes. Tropical Doctor, 37, 85-88. doi:10.1258/004947507780609437

[6] Lewis, L.N., Hickey, M., Doherty, D.A. and Skinner, S.R. (2009) How do pregnancy outcomes differ in teenage mothers? A Western Australian study. The Medical Journal of Australia, 190, 537-541.

[7] Mahavarkar, S.H., Madhu, C.K. and Mule, V.D. (2008) A comparative study of teenage pregnancy. American Journal of Obstetrics \& Gynecology, 28, 604-607. doi:10.1080/01443610802281831

[8] Tebeu, P.M., Tantchou, J., Obama Abena, M.T., Mevoula, O.D. and Leke, R.J. (2006) Delivery outcome of adolescents in Far North Cameroon. Revue Medicale de Liege, 61, 124-127.

[9] Tebeu, P.M., Kemfang, J.D., Sandjong, D.I., Kongnyuy, E., Halle, G. and Doh, A.S. (2010) Geographic Distribution of Childbirth among Adolescents in Cameroon from 2003 to 2005. Obstetrics and Gynecology International.

[10] Maryam, K. and Ali, S. (2008) Pregnancy outcome in teenagers in East Sauterne of Iran. Journal of Pakistan Medical Association, 58, 541-544.

[11] Quinlivan, J.A. and Evans, S.F. (2002) The impact of continuing illegal drug use on teenage pregnancy outcomes: A prospective cohort study. British Journal of Obstetrics and Gynaecology, 109, 1148-1153. doi:10.1111/j.1471-0528.2002.01536.x

[12] Tebeu, P.M., Major, A.L., Ludicke, F., Obama, M.T., Kouam, L. and Doh, A.S. (2004) Devenir de l'accouchement aux âges extrêmes de la vie reproductive. Revue Medicale de Liege, 59, 455-459.

[13] Ebeigbe, P.N. and Gharoro, E.P. (2007) Obstetric complications, intervention rates and maternofetal outcome in teenage nullipara in Benin City, Nigeria. Tropical Doctor, 37, 79-83. doi:10.1258/004947507780609356

[14] Trivedi, S.S. and Pasrija, S. (2007) Teenage pregnancies and their obstetric outcomes. Tropical Doctor, 37, 85-88. doi:10.1258/004947507780609437

[15] Unfer, V., Piazze Garnica, J., Benedetto, M.R., Castabile, L., Gallo, G. and Anceschi, M.M. (1995) Pregnancy in adolescents. A case control study. Clinical \& Experimental Obstetrics \& Gynecology, 22, 161-164.

[16] MacKenzie, I.Z., Cooke, I. and Annan, B. (2003) Indications for caesarean section in a consultant obstetric unit over three decades. American Journal of Obstetrics \& Gynecology, 23, 233-238.

doi: $10.1080 / 0144361031000098316$

[17] Metello, J., Torgal, M., Viana, R., Martins, L., Maia, M. and Casal, E., et al. (2008) Teenage pregnancy outcome. Revista Brasileira de Ginecologia e Obstetrícia, 30, 620625. doi:10.1590/S0100-72032008001200006

[18] Bujold, E., Mehta, S.H., Bujold, C. and Gauthier, R.J. (2002) Interdelivery interval and uterine rupture. American Journal of Obstetrics \& Gynecology, 187, 11991202. doi: $10.1067 / \mathrm{mob} .2002 .127138$

[19] Huang, W.H., Nakashima, D.K., Rumney, P.J., Keegan, K.A. and Chan, K. (2002) Interdelivery interval and the success of vaginal birth after cesarean delivery. American Journal of Obstetrics \& Gynecology, 99, 41-44. doi:10.1016/S0029-7844(01)01652-0

[20] Yetman, T.J. and Nolan, T.E. (1989) Vaginal birth after cesarean section: A reappraisal of risk. American Journal of Obstetrics \& Gynecology, 161, 1119-1123.

[21] Olausson, P.O., Cnattingius, S. and Haglund, B. (2001) Does the increased risk of preterm delivery in teenagers persist in pregnancies after the teenage period? British Journal Obstetrics Gynecology, 108, 721-725.

[22] Anate, M. and Akeredolu, O. (1996) Pregnancy outcome in elderly primigravidae at University of Ilorin Teaching Hospital, Nigeria. East Africa Medical Journal, 73, 548551.

[23] Quinlivan, J.A. and Evans, S.F. (2004) Teenage antenatal clinics may reduce the rate of preterm birth: A prospective study. British Journal of Obstetrics and Gynecology, 111, 571-578. doi:10.1111/j.1471-0528.2004.00146.x

[24] Phipp,s M.G. and Sowers, M. (2002) Defining early adolescent childbearing. American Journal of Public Health, 92, 125-128. doi:10.2105/AJPH.92.1.125

[25] Ndyomugyenyi, R. and Magnussen, P. (1999) Anaemia in pregnancy: Plasmodium falciparum infection is an important cause in primigravidae in Hoima district, western Uganda. Annals of Tropical Medicine and Parasitology, 93, 457-465. doi:10.1080/00034989958195

[26] Ebeigbe, P.N. and Gharoro, E.P. (2007) Obstetric complications, intervention rates and maternofetal outcome in teenage nullipara in Benin City, Nigeria. Tropical Doctor, 37, 79-83. doi: 10.1258/004947507780609356

[27] Barnet, B., Duggan, A.K. and Devoe, M. (2003) Reduced low birth weight for teenagers receiving prenatal care at a school-based health center: Effect of access and comprehensive care. Journal of Adolescent Health, 33, 349-358. doi:10.1016/S1054-139X(03)00211-8

[28] Malviya, M.K., Bhardwaj, V.K., Chansoria, M. and Khare, S. (2003) Anthropometric profile and perinatal outcome of babies born to young women ( $<18$ years). Indian Pediatrics, 40, 971-976. 